\title{
A Method for Estimating the Regional Initial and Constant Loss for Design Flood Estimation in West Peninsular Malaysia
}

\author{
(Date received: 23.11.12/Date accepted: 17.09.13) \\ Sazali Osman ${ }^{1,2}$, Ismail Abustan ${ }^{1}$, Rozi Abdullah ${ }^{1}$

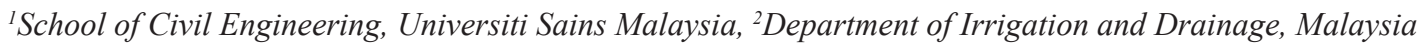 \\ E-mail:1,2sazaliosman@gmail.com,.'ceismail@eng.usm.my, ${ }^{1}$ cerozi@eng.usm.my
}

\begin{abstract}
Floods are known as one of the world's most frequent and devastating events. Techniques to predict and estimate the size of floods is depend on the availability of hydrological data. Using the conceptual of lump model, rainfall-runoff method is widely used in design flood estimation, which represents the input of rainfall and catchment characteristics such as rainfall depth, rainfall intensity, baseflow and losses. To calculate the catchments runoff, amount of losses shall be determine accurately by considering various source of the rainfall losses such as evaporation, infiltration, interception, depression storage and loss in groundwater recharge. In Malaysia, the common technique to estimate the hydrological losses is using initial and constant loss method. Furthermore, the value has been used in Urban Stormwater Manual for Malaysia(USMA) are adopted from the other literatures which is not represented the value from local catchment.

The objective of this study is to derive the initial and constant loss values using the data from selected local catchments in west Peninsular Malaysia. The calculated initial and constant loss will be further used to derive design flood discharge based on the design rainfall. An initial loss and constant loss model was examined in this study to observe the loss rate parameters in heterogeneous catchments and evaluate their significance as well as their potential influence on design peak floods. The study has been utilised the rainfall and runoff data from 113 storms over 15 catchments. The loss parameters were obtained from model optimization using the HEC-HMS Modeling program. From the analyses, the median initial loss is $21.54 \mathrm{~mm}$ with the standard deviation $7.85 \mathrm{~mm}$. The value shows higher than the value adopted in USMA. Meanwhile, the value for constant loss is $8.07 \mathrm{~mm}$ which between the range of USMA. Based on the findings of design initial loss analyses, the values of initial loss were 49.3, 57.6, 64.1, 69.4, 73.3 and 76.6 for ARI 2,5,10,20,50 and 100, respectively. The percentage error between design initial loss and constant loss method and flood frequency method shows good results which are most of the percentage error less than $35 \%$. It shows that the design initial loss and constant loss method produce reasonable accurate results when compared to the rainfall-runoff method and flood frequency method. Based on the findings, it can be suggested that the regional design initial loss and the constant loss rates would be able to serve reasonably well in determining catchment loss for the design purposes.
\end{abstract}

Keywords: Constant Loss, Design Peak Flood, Initial Loss, Loss Rate, Rainfall-Runoff

\subsection{INTRODUCTION}

THE current scenario of natural disaster gives more significant impact in term of damages, human's death; loss of economic revenue, social activities and many others. In Malaysia, flooding is the largest disaster that occurs in every year which caused millions of dollars of damage. These annual flood events have been classified as normal flood which occur during the northeast monsoon season between November and March in the east coast of Peninsular Malaysia. Meanwhile, major floods occur once every few year such as in 1926, 1971, and 1997 and recently December 2006/January 2007. The 2006/2007 flood events has been caused 18 casualties with more than 110,000 evacuees which is the estimated damages exceed RM 1.5 billion (excluding losses caused by the economic downturn) [1]. These flooding events occurred in several states which are Johor, Negeri Sembilan, Melaka and Pahang.

The application of rainfall - runoff models in the design flood estimation often used in many catchment studies. For design purposes, complex rainfall-runoff processes are often simplified for easy analysis, taking into consideration the main factors that influence the hydrological mechanisms. The runoff volume for a particular catchment is highly dependent on the rainfall depth and losses. The determination of catchment rainfall depth is depending on the rainfall intensity, storm duration, and distribution of the storm event [2]. The accuracy to estimate the catchment rainfall is rely on the distribution of rainfall gauges and the period of the rainfall data has been collected. Meanwhile, the losses of rainfall more difficult to estimate because of various factors influence the catchment losses such as evaporation, interception by vegetation, infiltration into the soil and retention on the surface, otherwise known as depression storage [3]. Losses are defined as the difference between total rainfall and the amount of runoff that reaches the outlet of a catchment area [3]. Although there are many methods for estimating hydrologic losses, some of these methods require field data measurements such as the Green and Ampt method and Horton Infiltration method [4,5]. As field measurement was not conducted in this study, empirical methods such as the initial loss and constant loss method was considered to be more suitable. The method has been used in the Urban Stormwater Manual Malaysia [6]. In this manual, the initial and constant loss values were adopted from recommended values by Chow et al. [7]. Further, for previous 
catchment condition, the initial loss is $10 \mathrm{~mm}$ and the constant loss is between $3-10 \mathrm{~mm} / \mathrm{hr}$ for loam soil. In Australia, the initial and constant loss values are varies between regions. For example, an initial loss value in Victoria is between $15-20 \mathrm{~mm}$ but for South Australia, the initial loss is $10 \mathrm{~mm}$ [8]. Findings by Saleh et al., the initial and constant loss method produced better results on runoff simulation compared with the Green and Ampt method for Kan Catchments in Iran [9]. In Malaysia, although the initial and constant loss method widely used in calculating catchment runoff, the initial and constant loss values frequently calculated during model calibration. This technique is not suitable for the catchment without hydrological gauges data. Therefore, the suggested values in the literatures which come from various study in other countries often used in the analysis. Meanwhile, initial loss and constant loss is one of the models within the HEC-HMS rainfall-runoff model. Although this loss model is difficult to apply in ungauged areas due to lack of direct physical relationship of parameters to catchment properties, it is well-established and widely used in many countries, especially in the United States [5,8].

In this model, initial loss represents loss of rainfall due to interception and depression storage while constant loss represents loss due to infiltration [8]. Interception storage is the amount of rainfall abstracted before reaching the ground [3]. There are several ways that interception occurs: interception loss, which is the precipitation stored temporarily by the vegetation but finally evaporated, stem-flow which is the flow of water down trunks and stems of plants, and though-fall, which is the process of excess rainwater dripping off leaves onto the ground surface [10]. By and large, most of the interception storage is evaporated immediately after precipitation ceases. Depression storage comprises puddles, ditches and other depressions in the catchment topography. It can be defined as water that is required to fill the depressions prior to the beginning of overland flow. The magnitude of depression storage naturally varies depending on the nature of the surface of the catchment.

Infiltration is usually defined as absorption of water into soil. If the soil is completely saturated or completely compacted, water will be considered as surface water [3]. During continuous rain the infiltration will start at a high value and decrease rapidly at a constant value rate. The infiltration rate during a storm varies because of the change in the condition of the soil during the storm. The causes for changing soil conditions and consequently decreasing infiltration capacity during the storm are various and complex.

Due to the unavailability, complexity, and difficulty in determining the loss parameters in local catchment, which consists of many components within the hydrological and meteorological processes, this study explores the feasibility of a simplified loss model using regional initial loss and constant loss. Findings from this study hopefully can be used as a guide to the hydrologist or designer for determining design flood values.

\subsection{STUDY AREA}

This study covers the west coast of Peninsular Malaysia comprising 15 catchments in 6 states namely Pulau Pinang, Perak, Selangor, Wilayah Persekutuan Kuala Lumpur, Negeri Sembilan and Melaka [11]. The climate of the region is tropical with average temperatures ranging from $21^{\circ} \mathrm{C}$ to $32^{\circ} \mathrm{C}$ throughout the year and the mean relative humidity is $80 \%$.

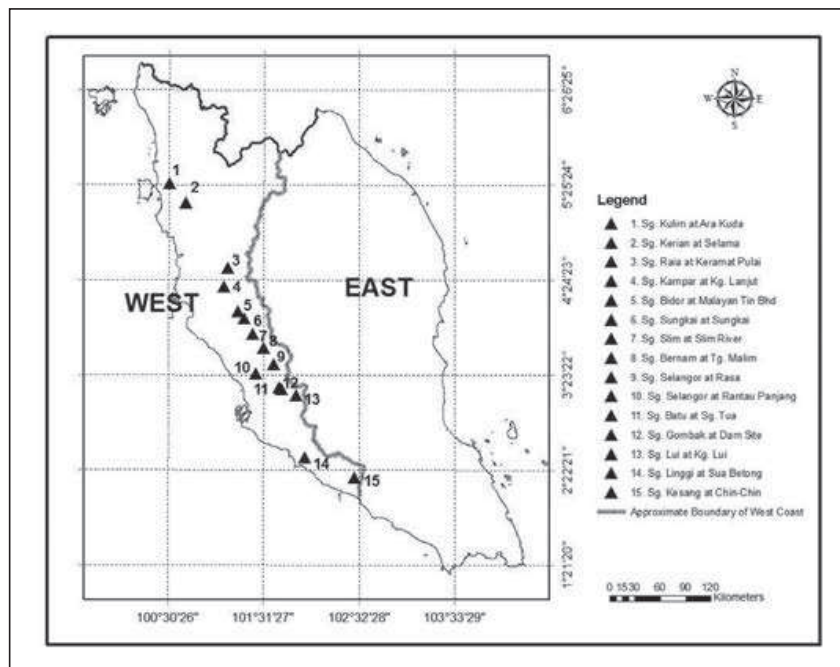

Figure 1: Location of the study area and gauging stations [11]

Situated in the equatorial zone, the climate is governed by northeast and southwest monsoons. The northeast monsoon occurs from November to March and Southwest monsoon from May to September [12]. These major monsoon seasons are separated by two relatively short inter-monsoon seasons (in April and October) which usually record heavy rainfall $[13,14]$. However, floods can occur during any month of the year. Annual rainfalls vary between $1700 \mathrm{~mm}$ and $3600 \mathrm{~mm}$ and the mean monthly rainfall ranges from $115 \mathrm{~mm}$ to $314 \mathrm{~mm}$ [13]. Figure 1 shows the general layout of the locations of the 15 gauging stations in the study area.

The majority of the catchments are mountainous and hilly undulating land, except for the southern part of the study area, which is dominated by low-lying undulated land. The highest altitude at approximately 2,131 MSL is located at Bidor catchment and the lower altitude is $12 \mathrm{MSL}$ at Sg. Kesang at Chin-Chin gauging station. The majority of the catchments, especially in the upper region, is virgin forest while the lower undulating hills areas are cultivated with rubber and fruit trees. The Ara Kuda catchment, together with other catchments in the southern part, is located in low-lying undulating land, which has been cultivated with rubber and paddy fields. Geologically, granite soil consisting of fine to coarse sand and clay covers in hilly and mountainous area towards the middle part for most of the catchments. A clayey loam soil grading to a fine sandy loam covers the lower part of the low-lying undulating catchments. Table 1 shows detail of catchment characteristics for each catchment in the study area.

\subsection{METHODOLOGY}

The initial loss and constant loss parameters in this study were derived using a rainfall-runoff model software called Hydrologic Engineering Center's Hydrologic Modeling Software (HECHMS). Developed by the US Army Corps Engineers, HEC-HMS version 3.3 simulates the rainfall-runoff processes of catchment systems and allows the modeler to choose between numerous runoff parameterizations [15]. For this study, the Clark unit hydrograph was used to apply the transformation routine. No baseflow function was used because the baseflow separated before the streamflow hydrograph was entered in the model. 
Table 1: Characteristics of the catchments [11]

\begin{tabular}{|c|c|c|c|c|c|c|c|}
\hline Site & $\begin{array}{c}\text { Gauge } \\
\text { ID } \\
\text { Number }\end{array}$ & $\begin{array}{c}\text { Catchment } \\
\text { Name }\end{array}$ & Gauging Station Name & $\begin{array}{c}\text { Record } \\
\text { Length } \\
\text { (Years) }\end{array}$ & $\begin{array}{c}\text { Catchment } \\
\text { Area } \\
\left(\mathbf{k m}^{2}\right)\end{array}$ & $\begin{array}{c}\text { Main river } \\
\text { length } \\
(\mathbf{k m})\end{array}$ & $\begin{array}{c}\text { Main river } \\
\text { slope } \\
\text { (weighted sum) } \\
(\mathbf{m} / \mathbf{k m})\end{array}$ \\
\hline 1 & 5405421 & Ara Kuda & Sg. Kulim at Ara Kuda & 48 & 130 & 30.12 & 6.72 \\
\hline 2 & 5206432 & Selama & Sg. Selama at Selama & 46 & 631 & 46.70 & 12.37 \\
\hline 3 & 4511468 & Raia & Sg. Raia at Keramat Pulai & 21 & 190 & 37.81 & 33.82 \\
\hline 4 & 4311464 & Kampar & Sg. Kampar at Kg. Lanjut & 27 & 446 & 54.71 & 18.90 \\
\hline 5 & 4012401 & Bidor & Sg. Bidor at Malayan & 21 & 210 & 34.59 & 21.11 \\
\hline 6 & 3913458 & Sungkai & Sg. Sungkai at Sungkai & 48 & 289 & 44.57 & 19.72 \\
\hline 7 & 3814416 & Slim & Sg. Slim at Slim River & 43 & 455 & 50.85 & 16.10 \\
\hline 8 & 3615412 & Malim & Sg. Bernam at Tg. Malim & 50 & 186 & 25.41 & 45.77 \\
\hline 9 & 3516422 & Rasa & Sg. Selangor at Rasa & 38 & 322 & 37.82 & 23.91 \\
\hline 10 & 3414421 & R.Panjang & Sg. Selangor at Rantau & 40 & 1450 & 75.14 \\
\hline 11 & 3216439 & Batu & Sg. Batu at Kg. Sg. Tua & 11 & 56 & 14.8 & 8.27 \\
\hline 12 & 3217401 & Gombak & Sg. Gombak at Dam Site & 8 & 85 & 64.5 \\
\hline 13 & 3118445 & Lui & Sg. Lui at Kg. Lui & 45 & 68 & 15.48 & 14.36 \\
\hline 14 & 2519421 & Linggi & Sg. Linggi at Sua Betong & 49 & 527 & 59.8 & 7.38 \\
\hline 15 & 2224432 & Kesang & Sg. Kesang at Chin - Chin & 50 & 172 & 33.95 & 2.4 \\
\hline
\end{tabular}

Prior to that, initial and constant loss rate method was used to determine the hydrologic losses for the study catchments. The model optimizes the parameters so that the computed hydrograph will closely match the observed hydrograph. As the model parameters are not measured, the parameters had to be determined by calibration. In the absence of any calibrated values, published recommended values of the parameters as specified in the HEC-HMS User's Manual served as a guide for the initial estimates [15]. The main steps to derive rainfall-runoff model parameters as well as initial loss and constant loss values are illustrated in Figure 2.

The process starts with obtaining rainfall and streamflow data and rating curves. Rainfall and streamflow data were obtained from Department of Irrigation and Drainage Malaysia. Next, a large number of rainfall and runoff data were screened and scrutinized by evaluating the rating curve and rainfallrunoff volume. Storm events that showed poor hydrograph were excluded, as well as rainfall-runoff events that produced runoff volumes larger than rainfall volumes.

The next step is the model calibration and parameter optimization. The rainfall-runoff model was run using HEC-HMS software to optimize the model parameters via optimization techniques that minimize errors between the observed and simulated values of runoff. The model parameter derived by HEC-HMS is divided into three components: the loss component is represented by initial loss and constant loss, the transform component is shown by the Clark unit hydrograph and the baseflow component which is not used in this study. These two components were optimized, and the optimizing parameters will be used for further analysis. In order to evaluate the performance of the model calibration, a model-fit efficiency, EFF [16], or frequently called as coefficient of determination, $\mathrm{r}^{2}$ equation was used.
The equation is written as follow:

$$
E F F=\frac{\left.\sum_{i=1}^{n}\left(Q m_{i}-Q m\right)^{2}-\sum_{i=1}^{n}\left(Q m_{i}-Q s_{i}\right)^{2}\right)}{\sum_{i=1}^{n}\left(Q m_{i}-Q m\right)^{2}}
$$

where

$E F F=$ coefficient of efficiency

$Q m_{i}=$ measured direct runoff at time i

$Q m=$ average measured direct runoff for the storm

$Q s_{i}=$ simulated direct runoff at time i

$n=$ number of simulated hydrograph ordinates

At the testing stage, the optimized value for initial loss and constant loss was tested for outlier. The box plot method was selected for observing and determining the outlier value for three groups of parameters, which are initial loss, constant loss and the percentage of runoff. The percentage of runoff was examined to make sure that only reasonable runoff rates for the study area are chosen. After that, using the HEC-HMS software, the design initial loss values were determined through trial and error to match the simulated design peak flood and calculated design peak flood obtained from flood frequency analysis. Together with the design initial loss values, the design rainfall was used as input for rainfall amount.

Theoretically, rainfall is usually not evenly distributed over an area with rainfall amount decreasing over distance from the storm centre. Within the study area, it was observed that large variations in rainfall amount can occur over short distances, particularly when thunderstorms dominate. Therefore, the areal reduction factors of Hydrological Procedure No. 1 [17] were 


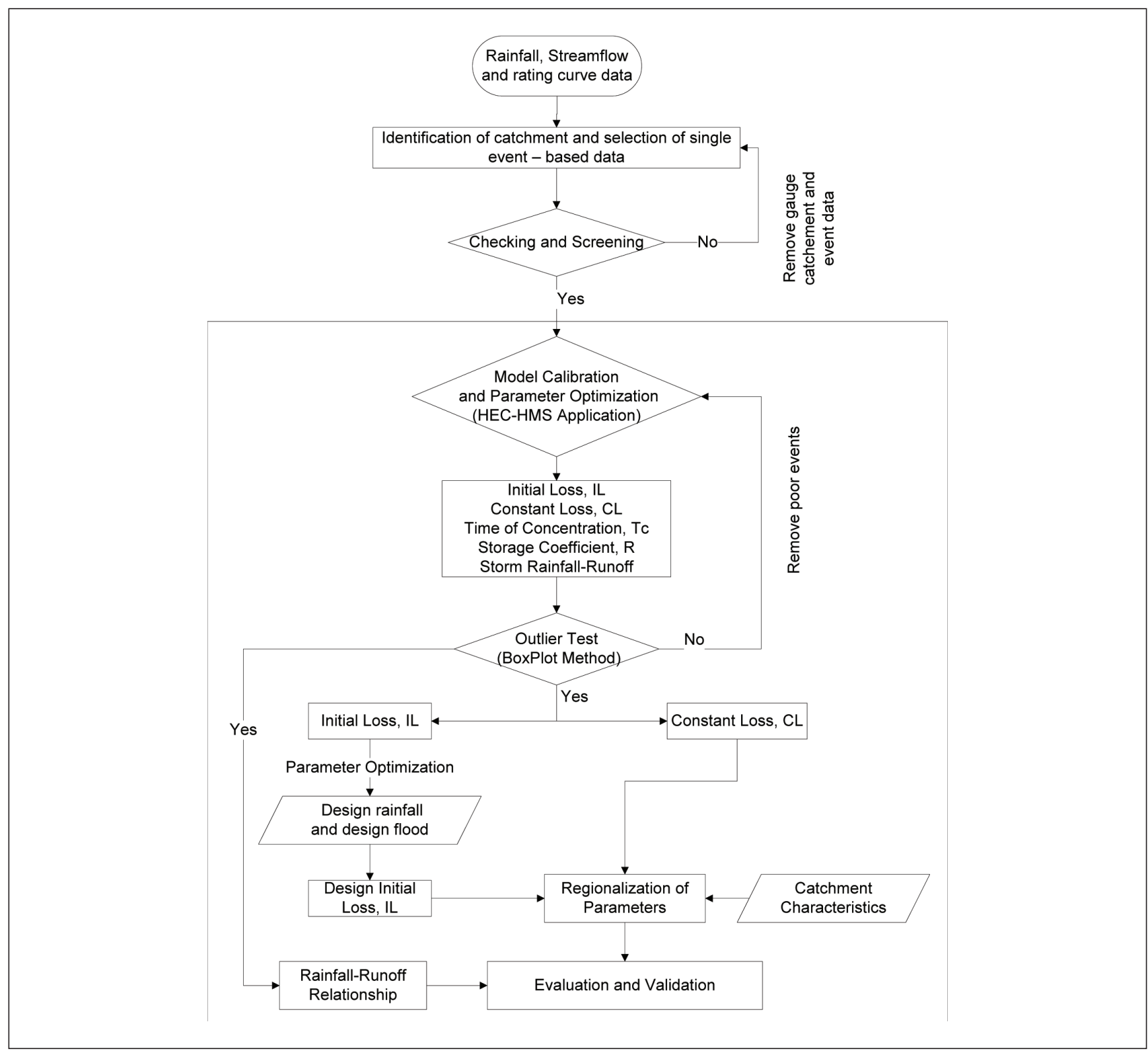

Figure 2: Methodology flowchart for developing regional initial loss and constant loss parameters

adopted for this study. Also used in this study were temporal patterns, which represent the critical duration of design rainfall to give maximum peak discharge. Various durations of temporal pattern were used to simulate the highest peak discharge. As with the areal reduction factors, temporal patterns also came from Hydrological Procedure No. 1 [17].

The following step focuses on the analysis of regionalization for initial loss and constant loss parameters. Regionalization involves the correlation of the parameters with catchment characteristics that influence the loss parameters. The catchment characteristics can be physical parameters such as area, length, slope, landuse and types of soils as well as storm characteristics such as rainfall intensity. For this study, regionalization correlates loss parameters with catchment area, length, slope, percentage of forest area and the rainfall intensity. The performance of correlation was examined using coefficient of determination, $r^{2}$ of the observed and computed values.

\subsection{EVALUATION AND VALIDATION}

The performance of the developed regional equations of initial and constant loss parameters was validated and tested by comparing the design flood values for three types of calculation methods. The three methods were described as:

i. Flood frequency analysis (FF)

ii. Design initial loss and constant loss (DIL\&CL)

iii. Rainfall-runoff relationship (RR)

In this study, the FF method was carried out using the Extreme Value Type I (EVI) distribution since the distribution method are used in existing Hydrological Procedure No. 1 [17]. The EVI also widely used in many hydrological analysis and flood design where commonly produce reasonable results. The proportion of total rainfall that becomes runoff during a storm event represents the rainfall-runoff relationship. This RR is developed such that the volume of runoff can be estimated from design rainfall. For the purpose of evaluation, the RR was 
derived using the same storm events as those used in generating design initial loss and constant loss.

The design flood calculated by DIL\&CL and RR method were performed using HEC-HMS rainfall-runoff model. During model simulation, the average value of calibrated Clark unit hydrograph parameters for each catchment was used as an input for model transform component.

\subsection{RESULTS AND DISCUSSION}

\subsection{Model Calibration and Parameter Optimization}

The calibration and optimization of hydrographs using HECHMS provided satisfactory results for all the 113 storm events. Checking and screening of storms using the box plot method for parameters initial loss, constant loss and percentage direct runoff was conducted, and finally 92 storms were used for determining regional design initial loss and regional constant loss as well as regional rainfall-runoff relationships. The distribution pattern of percentage runoff, initial loss, and constant loss could be observed from the box plot in Figure 3. Data showing outlier or out of range were eliminated. Unreasonable values of initial loss and constant loss were also discarded. It can be observed from the box plot that the initial loss for Selama, Raia, Kampar, Slim and Malim are well out of range and have a tail towards a larger value or positively skewed. At the same time, Malim catchment shows the outlier's value for the percentage of the direct runoff.

Data consistency was also checked by evaluating the distribution of the data. For example, from Figure 3, no outliers for constant loss values were plotted for the Malim catchment; however, the data distribution had a bigger range, indicating a large deviation from the mean. Therefore, some values were rejected to improve the data consistency. This approach puts the initial loss and constant loss for that catchment between the acceptable ranges.

The optimized rainfall-runoff model parameters for all catchments are presented in Table 2 . The average value for the model efficiency varies from 0.946 to 0.983 , which is acceptable as optimization techniques inherently include assumptions and approximations. At the same time, the selection of storms is also considered based on the shape of the simulated hydrograph and the beginning of the rising point. Plotted hydrograph with early start than rainfall excess are not used in further analyses.

Table 3 shows the summary statistics of 92 values of initial loss and constant loss. The median values for initial loss and constant loss are $21.54 \mathrm{~mm}$ and $8.07 \mathrm{~mm} / \mathrm{hr}$, respectively. Both values were generally accepted compared with other values obtained from other studies $[5,6,18]$. A higher standard deviation for constant loss value was noted, which may have been caused by the variation in storm bursts during calibration analysis. These results were show a wide variability from storm to storm and catchment to catchment. The effect of terrain and localized rainfall events will be influenced the calibration results. Although rainfall was assumed to be averagely tabulated at the whole catchment in the calibration analysis, in reality, rainfall drop is often concentrated in a localized area, especially in the study catchments where thunderstorms dominated and further storms normally occurred in short durations with high intensities.
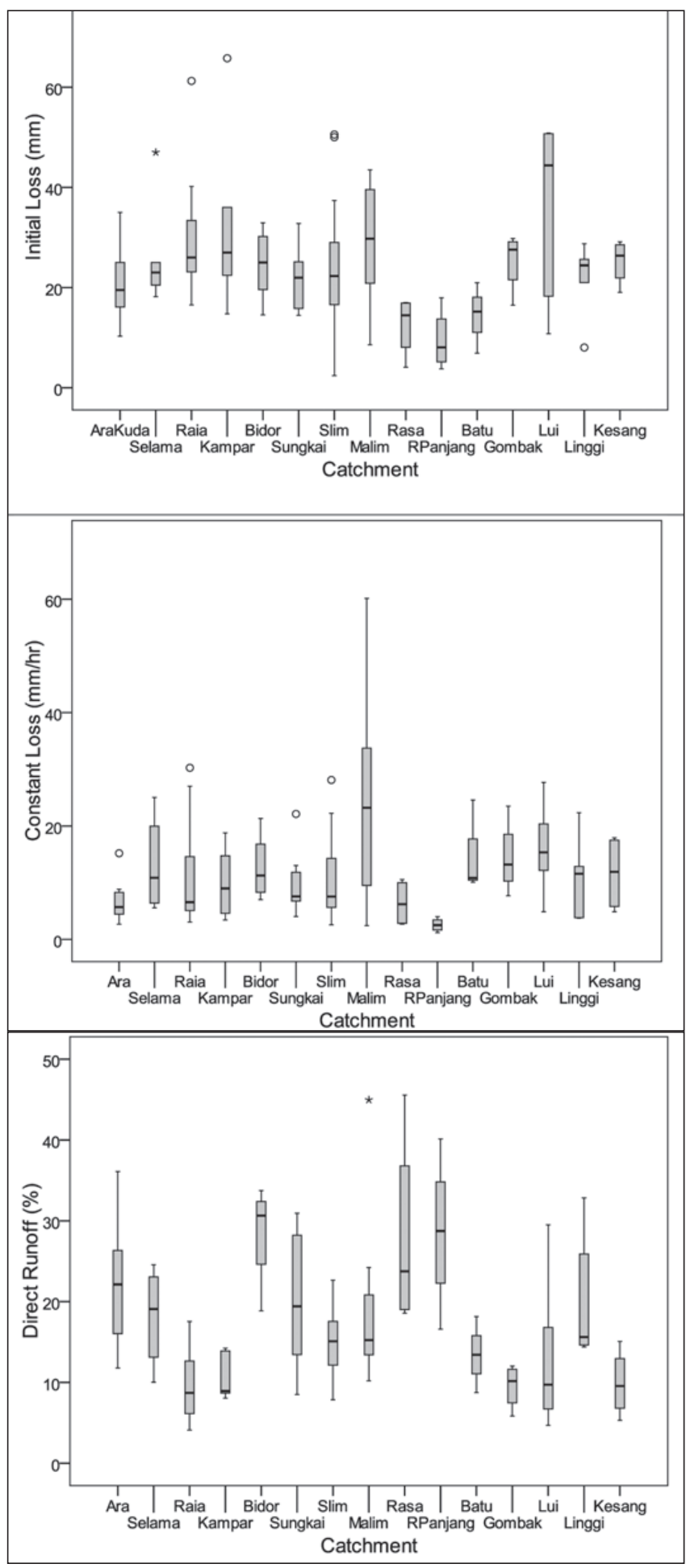

Figure 3: Box plot for percentage direct runoff, initial loss and constant loss for 113 storm events

\subsection{Analysis of Design Initial Loss}

Median values of initial loss and constant loss were used with average values of Clark unit hydrograph and baseflow parameters to obtain the design initial loss as shown in Table 2. Design initial loss was obtained by matching the simulated peak flood and design peak flood value from flood frequency analysis. The final value of design initial loss for various design 
Table 2: Optimized values of rainfall-runoff model parameters in all catchments

\begin{tabular}{|c|c|c|c|c|c|c|c|}
\hline Catchment & $\begin{array}{l}\text { Area } \\
\left(\mathrm{km}^{2}\right)\end{array}$ & $\begin{array}{l}\text { Initial loss } \\
\quad(\mathrm{mm})\end{array}$ & $\begin{array}{l}\text { Constant loss } \\
(\mathrm{mm} / \mathrm{hr})\end{array}$ & $\begin{array}{c}\text { Time of } \\
\text { Concentration } \\
\text { (hr) }\end{array}$ & $\begin{array}{c}\text { Storage Coefficient } \\
\text { (hr) }\end{array}$ & $\begin{array}{c}\text { Baseflow } \\
\left(\mathbf{m}^{3} / \mathbf{s}\right)\end{array}$ & $\begin{array}{c}\text { Model } \\
\text { Efficiency } \\
\text { (EFF) }\end{array}$ \\
\hline Ara Kuda & 130 & 20.00 & 5.09 & 9.82 & 8.82 & 5.40 & 0.976 \\
\hline Selama & 631 & 21.00 & 9.75 & 23.13 & 19.90 & 33.34 & 0.960 \\
\hline Raia & 190 & 24.72 & 5.94 & 5.51 & 6.49 & 7.72 & 0.968 \\
\hline Kampar & 446 & 24.72 & 6.81 & 8.75 & 9.12 & 12.65 & 0.963 \\
\hline Sungkai & 210 & 25.00 & 11.29 & 8.50 & 7.51 & 15.54 & 0.959 \\
\hline Bidor & 289 & 21.10 & 7.02 & 13.00 & 5.98 & 22.76 & 0.954 \\
\hline Slim & 455 & 20.37 & 7.18 & 17.56 & 7.91 & 15.44 & 0.979 \\
\hline Malim & 186 & 28.90 & 15.38 & 4.14 & 5.34 & 10.55 & 0.967 \\
\hline Rasa & 322 & 16.83 & 9.43 & 7.66 & 4.67 & 19.03 & 0.983 \\
\hline R.Panjang & 1450 & 6.60 & 2.13 & 54.05 & 21.97 & 153.11 & 0.946 \\
\hline Batu & 56 & 15.20 & 10.86 & 1.96 & 2.92 & 1.87 & 0.968 \\
\hline Gombak & 85 & 27.57 & 13.23 & 2.67 & 3.63 & 2.68 & 0.965 \\
\hline Lui & 68 & 18.30 & 12.20 & 9.15 & 4.64 & 3.04 & 0.966 \\
\hline Linggi & 527 & 25.00 & 12.00 & 27.34 & 32.28 & 16.38 & 0.962 \\
\hline Kesang & 172 & 26.38 & 11.93 & 12.28 & 11.62 & 3.98 & 0.963 \\
\hline
\end{tabular}

Table 3: Common statistical result of initial loss and constant loss parameter

\begin{tabular}{cccccccc}
\hline & Minimum & Maximum & First quartile & Third quartile & Mean & $\begin{array}{c}\text { Median } \\
\text { Deviationdard } \\
\text { Deviation }\end{array}$ \\
\hline $\begin{array}{c}\text { Initial } \\
\text { loss }\end{array}$ & 3.76 & 44.39 & 16.62 & 27.69 & 22.24 & 21.54 & 7.85 \\
$\begin{array}{c}\text { Constant } \\
\text { loss }\end{array}$ & 1.21 & 27.78 & 5.38 & 12.38 & 9.71 & 8.07 & 5.92 \\
\hline
\end{tabular}

return periods are shown in Table 4 and Figure 4. Overall, it can be seen that design initial loss increases proportionally with Average Recurrence Interval (ARI). Two catchments, namely Selama and Bidor, provide consistent values for different ARIs, which show no significant difference between low and high ARIs. Although all the study catchments are located within the same region, the variability of losses existed in response to the various factors that can influence the losses such as soil types, catchment slopes, rainfall characteristics and many other factors. For this study, optimized values of design initial loss depend on values of design rainfall and design peak flood. Higher design rainfall or lower design peak flood will increase design loss and vice versa.

\subsection{Regression Equation of Loss Model}

In this study, the relationship between initial loss and constant loss with the physical, landuse and storm characteristics was evaluated. Catchment size, main river length and main river slope, the percentage of forested area for each catchment are correlated to loss parameters. Figure 5 shows the graphical relationship of the initial loss and constant loss to the physical and landuse characteristics of the catchment. Result show that $\mathrm{R}^{2}$ values is less than 0.5 for the correlation between constant loss and the catchment area, mainstream length, mainstream slope and forest area. However, the correlation between constant loss with catchment area and length show slightly significant which is the $\mathrm{R}^{2}$ values is 0.316 and 0.334 , respectively. This result shows that, in general, initial loss has no significant correlation with catchment area and length, which are parameters distributed along the median line. However, there are slightly low correlations between constant loss and catchment area and length. Constant loss decreases when catchment area and length increase. This result seems logical, meaning that larger catchment sizes or longer stream lengths have smaller constant loss [19]. Moriasi et al. define the $\mathrm{R}^{2}$ larger than 0.75 are classified as very good

Table 4: Optimize design initial loss values for 10 catchments

\begin{tabular}{ccccccc}
\hline Catchment & 2 ARI & 5 ARI & 10 ARI & 20 ARI & 50 ARI & 100 ARI \\
\hline Ara Kuda & 50.5 & 72.0 & 87.0 & 96.0 & 103.0 & 110.5 \\
Selama & 26.0 & 25.5 & 25.0 & 25.0 & 25.0 & 25.0 \\
Raia & 52.5 & 63.5 & 73.5 & 79.5 & 84.0 & 90.5 \\
Kampar & 44.0 & 48.0 & 52.0 & 56.0 & 59.0 & 62.5 \\
Bidor & 39.0 & 44.5 & 48.0 & 48.0 & 48.5 & 47.0 \\
Sungkai & 52.0 & 62.0 & 69.5 & 77.0 & 80.5 & 83.0 \\
Slim & 55.0 & 57.0 & 59.5 & 61.5 & 62.5 & 65.0 \\
Malim & 53.0 & 62.5 & 69.5 & 75.5 & 78.5 & 80.5 \\
R.Panjang & 67.5 & 74.0 & 79.0 & 87.5 & 95.0 & 101.0 \\
Lui & 53.0 & 67.0 & 78.0 & 87.5 & 97.0 & 100.5 \\
\hline Mean & 49.3 & 57.6 & 64.1 & 69.4 & 73.3 & 76.6 \\
\hline
\end{tabular}




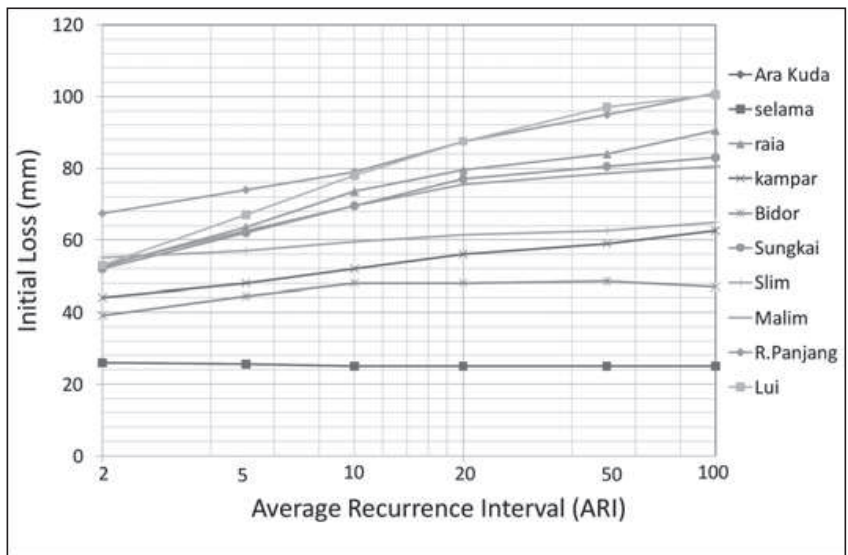

Figure 4: Graphical presentation of optimize design initial loss for 2, 5, 10, 20, 50 and 100 ARI for 10 selected catchments

and values between 0.5 and 0.75 are considered satisfactory meanwhile values lower than 0.5 as unsatisfactory [20]. The correlation strength between catchment characteristics and catchment loss varies between catchments where it depends on many factors such as the regions, data errors, soil type, climate and topography. Previous study by Pilgrim [19] and Hussein \& Othman [21] also produced various ranges of correlation results.

Correlation results between loss parameters and rainfall intensity as shown in Figure 6 show that $\mathrm{R}^{2}$ values for initial and constant loss is less than 0.1 . The initial loss was well distributed, whereas constant loss showed a very low positive relationship. It indicates the influence of storm intensity on rainfall losses was not clear for the tropical climate particularly within the study area. This result is similar to the previous study conducted by Asquith [5]. It could have occurred due to the set of rainfallrunoff data used in calibration which might be the catchment rainfall data are not uniformly tabulated at a whole catchment area [22]. The rainfall losses may also influence of soil hydraulic property which is not examine in this study [23]. After finalizing the analysis of initial loss and constant loss values, therefore, the regional design constant loss for the study area is $8.07 \mathrm{~mm} / \mathrm{hr}$ and the initial loss values were shown in Table 5.

\subsection{Rainfall-Runoff Relationship}

In this study, the rainfall-runoff relationship was developed using 92 storm data from 1970 to 2009 for 15 catchments along the west coast of Peninsular Malaysia, which is the same data used in deriving regional initial loss and constant loss. The plotting method followed the same method used in Hydrological Procedure No. 11 [24]. It means that the total design effective rainfall depth for a particular design ARI is similar to the direct runoff volume derived from the rainfall-runoff relationship.

Figure 7 shows the results of the rainfall-runoff relationship with the fitted equation. Storm data were scattered along the fitted line and distributed in an area less than $180 \mathrm{~mm}$ rainfall depth. For this study, there are two equations depending on the depth of rainfall, one for less than or equal $75 \mathrm{~mm}$ and another for greater than $75 \mathrm{~mm}$. The fitted equations are as follows:
Table 5: Initial loss values for various ARI

\begin{tabular}{ccccccc}
\hline $\begin{array}{c}\text { ARI } \\
\text { (years) }\end{array}$ & $\mathbf{2}$ & $\mathbf{5}$ & $\mathbf{1 0}$ & $\mathbf{2 0}$ & $\mathbf{5 0}$ & $\mathbf{1 0 0}$ \\
\hline & 49.3 & 57.6 & 64.1 & 69.4 & 73.3 & 76.6 \\
\hline
\end{tabular}
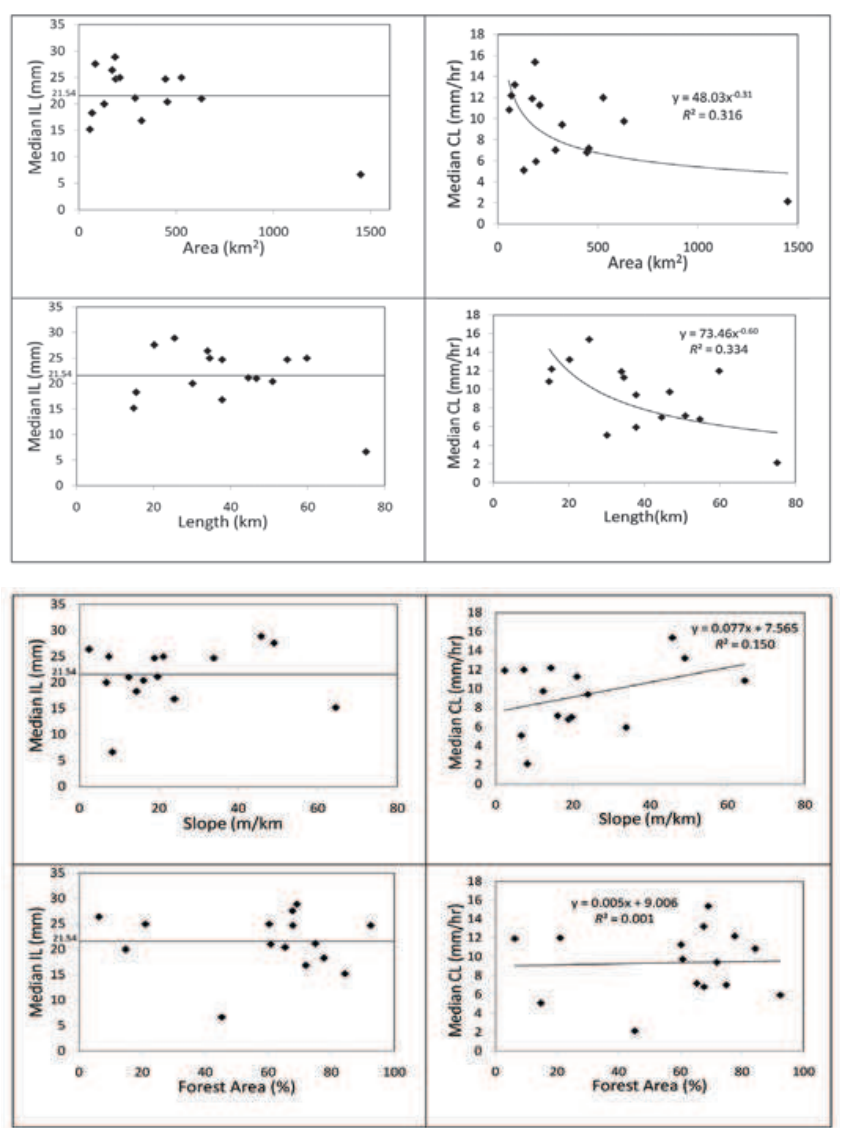

Figure 5: Median initial loss and median constant loss plotted with catchment characteristics of area, length, slope and percentage of forest area
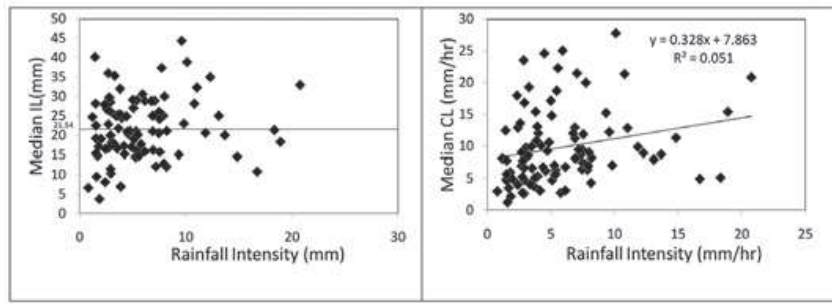

Figure 6: Median initial loss and median constant loss plotted with rainfall intensity 
$\mathrm{Q}=0.19 \mathrm{P}-1.1$ where, $\mathrm{P} \leq 75 \mathrm{~mm}$

$\mathrm{Q}=\mathrm{P} 2 /(\mathrm{P}+350)$ where, $\mathrm{P}>75 \mathrm{~mm}$

Where $\mathrm{P}=$ total storm rainfall in $\mathrm{mm}$ and $\mathrm{Q}=$ direct runoff in $\mathrm{m}^{3} / \mathrm{s}$

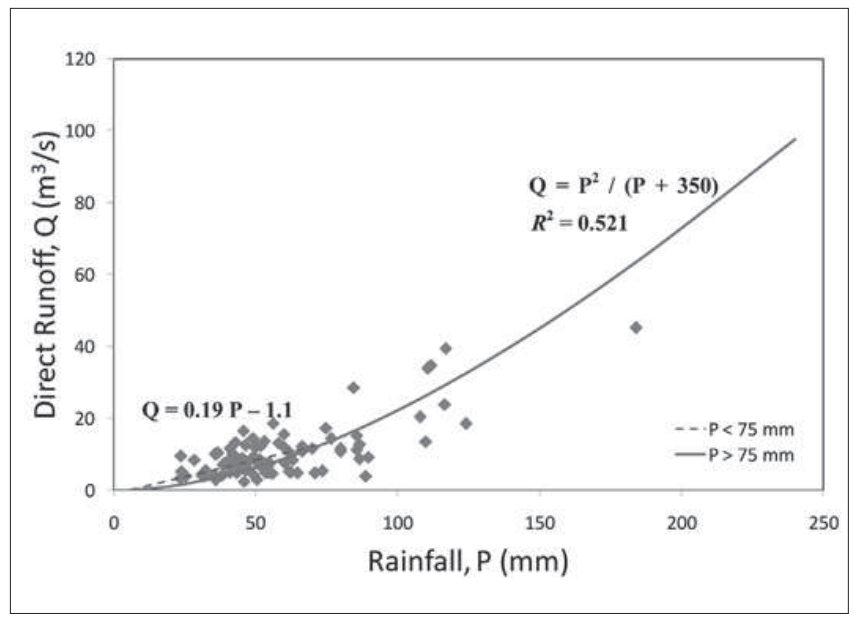

Figure 7: Rainfall-runoff relationship study catchments in west coast of Peninsular Malaysia

\subsection{Result Evaluation}

After finalizing the regional design initial loss and constant loss parameters, the applicability of the loss model was assessed through model evaluation. Design rainfall for various return periods were used as rainfall input to the HEC-HMS model. As described previously in the methodology section, the evaluation of the performance of developed regional design initial loss and constant loss parameters were carried out via three methods namely FF method, DIL\&CL method and RR method.

Out of the 15 catchments, 10 catchments were used to evaluate the loss model based on all three methods as mentioned above. Figure 8 shows the results of evaluation for loss model using DIL\&CL method and RR method and plotted against the results from flood frequency analysis. It can be seen that the performance of loss model using DIL\&CL method are satisfactory as compared to the RR method and FF method. Some catchments such as Lui, Kesang, Bidor, and Kampar provided better results, especially on higher return periods. When the design peak discharges for DIL\&CL method were compared with the RR method, better results were obtained because both methods were derived from the same data set. These results revealed the capability of the design initial loss and constant loss method to produce reliable values when used for design estimation within study area. However, some catchments show lesser estimated value of design peak discharge such as Bidor and R.Panjang. Others model parameters such as transformation parameter (time of concentration and storage coefficient) or baseflow value will influence the results. Higher value time of concentration reduces estimated peak discharge.
Moreover, the calculated result of peak discharges was extended by calculating the percentage residual error between DIL\&CL method and FF method as shown in Figure 9. It can be seen that the residual error mostly scatter tabulated along the range of 1 to $35 \%$. Better performance is shown for higher ARIs, which is sufficient for use in most flood protection design. These results further support previous findings in which initial loss values were uniformly tabulated when related to catchment characteristics [19]. Subsequently, the results also show that the design initial loss and constant loss method is a reliable method to be used for various sizes of catchment areas located within the limit of the catchment area used in the current study. In practice, larger catchments should be modified to small sub-catchment area which can improve the result of the analysis.

\subsection{CONCLUSION}

In this study, rainfall-runoff characteristics have been computed for four parameters, viz. initial loss, constant loss, time of concentration and storage coefficient which define the components of storm hydrograph parameters. For the study area the values of these parameters are further used for determination of regional design initial loss and constant loss. Based on the results analysis, the following conclusions were drawn:

1. The median initial loss and constant loss are $21.54 \mathrm{~mm}$ and $8.07 \mathrm{~mm} / \mathrm{hr}$, respectively. This result indicates the initial loss value is higher compared to the initial loss value in USMA, and however, the constant loss value is between the ranges.

2. Based on ARI 2, 5, 10, 20, 50 and 100, the initial loss values are 49.3, 57.6, 64.1, 69.4, 73.3 and 76.6, respectively. It was clearly indicated the loss values positively increase with the ARI and this result comparable values in ARR.

3. The regionalization analysis of constant loss with catchment, landuse and storm characteristics show no significant trend of correlation was identified. Therefore, the constant loss of study area is averaging as $8.07 \mathrm{~mm} / \mathrm{hr}$.

4. With these loss values, a comparison of the design peak discharges under the RR method and the FF method shows that the DIL\&CL method produce reasonable results within the study catchment area. The residual error analysis between DIL\&CL and FF method indicates that the most of percentage error less than $35 \%$.

5. On average, better performance can be observed for regional design initial loss and constant loss in study catchment areas. The percentage of error could be minimized by including other parameters such as soil types during the development of constant loss equations. The soil characteristics would be influence on the rainfall losses especially for rural catchment area. 
METHOD FOR ESTIMATING THE REGIONAL INITIAL AND CONSTANT

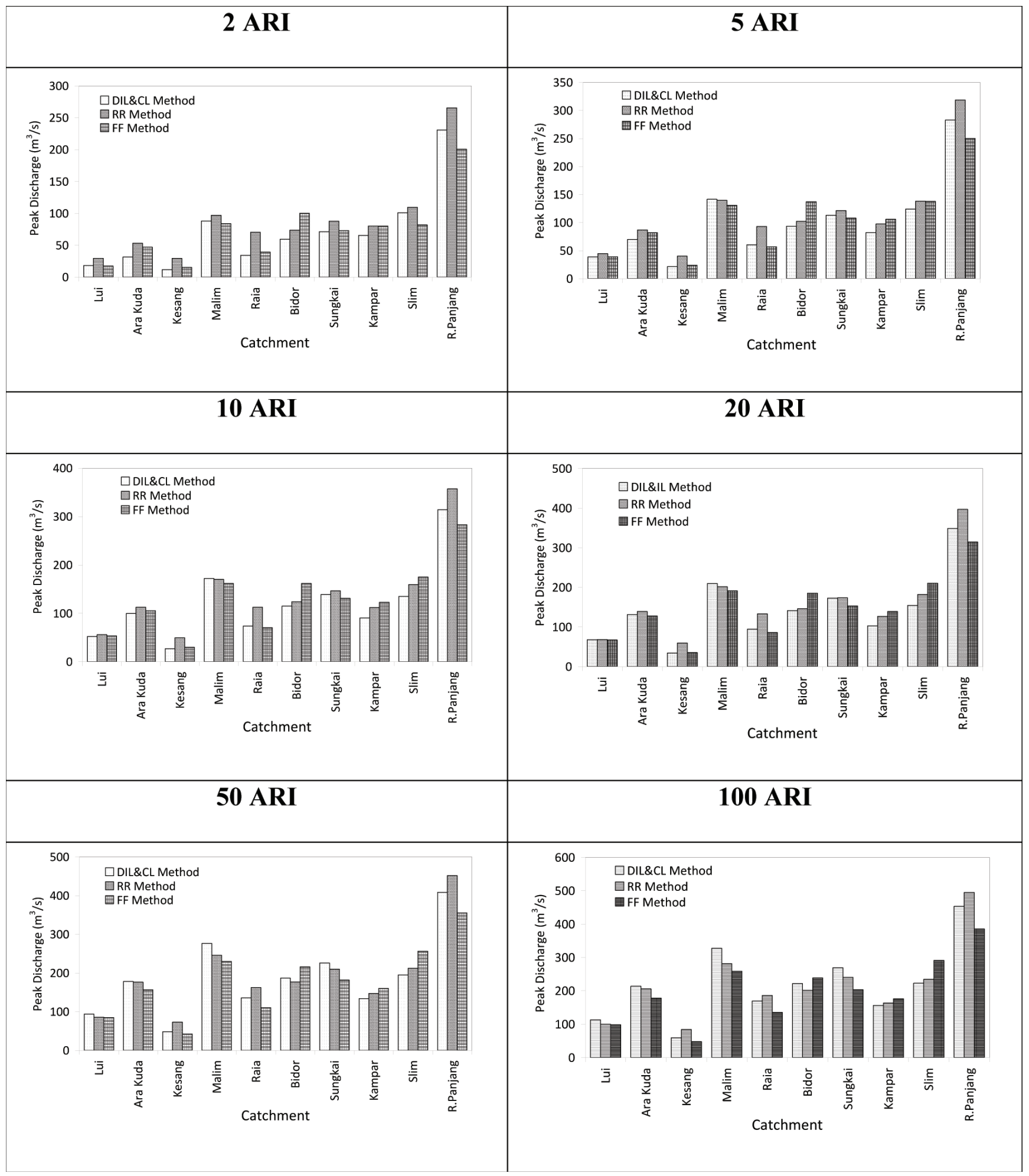

Figure 8: Design peak discharge for three methods; (i) rainfall-runoff loss method (RR) (ii) initial and constant loss method (IL \& CL) (iii) flood frequency method (FF) 


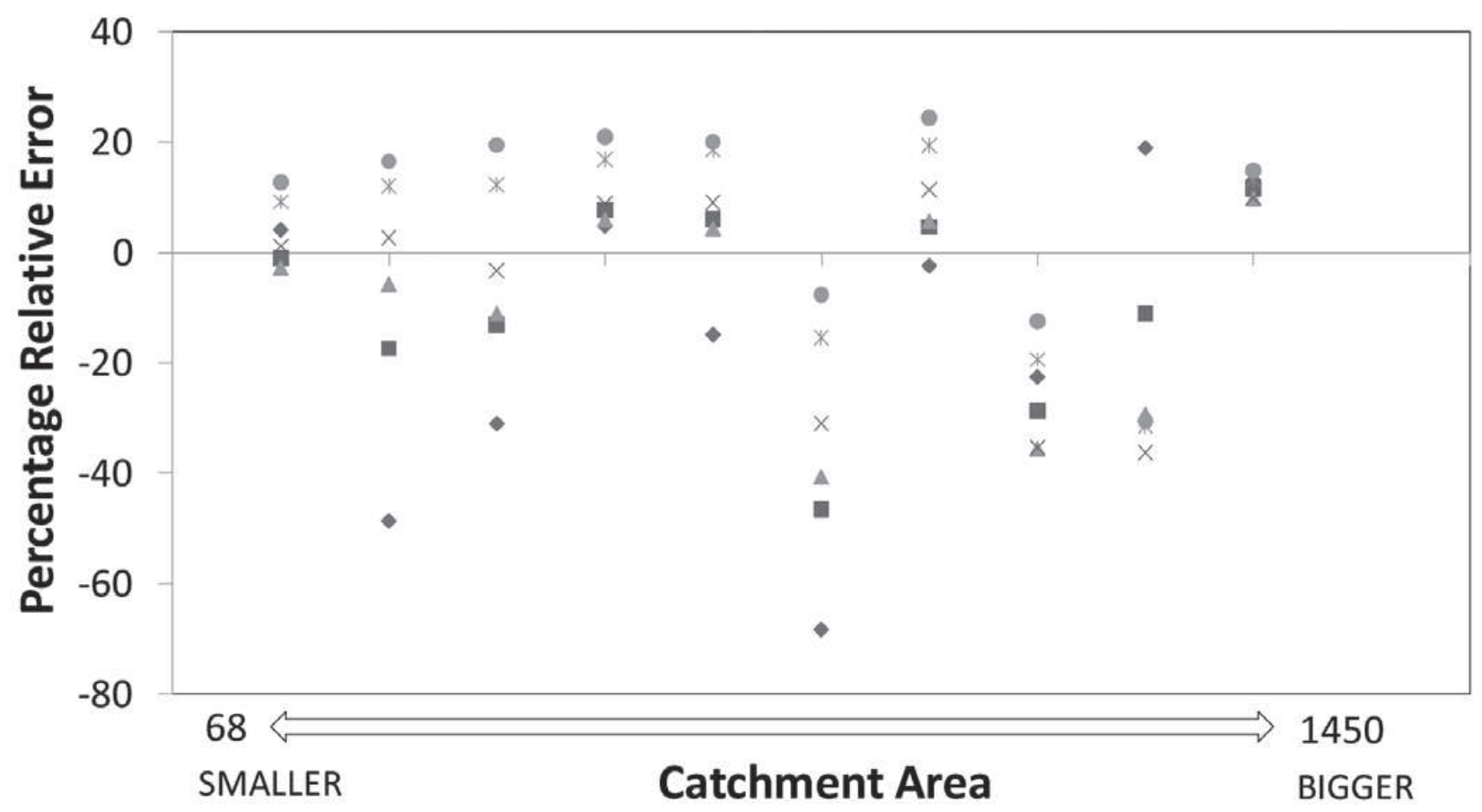

- 2 ARI $\backsim 5$ ARI $\triangle 10$ ARI $\times 20$ ARI $* 50$ ARI 100 ARI

Figure 9: Scatter plot of percentage residual error for 14 catchments in various ARI

\section{REFERENCES}

[1] A.H., Sulaiman. Flood and Drought Management in Malaysia. Keynote Lecture 2, National Seminar on Socio-Economic Impact of Extreme Weather and Climate Change, Putrajaya, 2007.

[2] M.El-Kafagee and A. Rahman, A study on initial and continuing losses for design flood estimation in New South Wales. 19th International Congress on Modelling and Simulation, Perth, Australia, 2011. http://mssanz.org.au/modsim2011.

[3] D.A. Chin, "Water Resources Engineering, Second Edition", Pearson Education Inc., Prentice Hall. Upper Saddle River, NJ, 2006.

[4] R.H. McCuen," "Hydrologic Analysis and Design, Second Edition” Prentice Hall. Upper Saddle River, NJ, 1998.

[5] W.H. Asquith, and M.C.. Roussel, "An initial-abstraction, constant-loss model for unit hydrograph modeling for applicable watersheds in Texas" U.S. Geological Survey Scientific Investigations Report 2007-5243, p.82., 2007.

[6] Department of Irrigation and Drainage (DID), Urban Stormwater Management Manual for Malaysia. 2011.

[7] V.T. Chow, D.R. Maidment and L.W. Mays. Applied Hydrology. McGraw -Hill International Edition, Singapore, 1988.

[8] Australian Rainfall and Runoff (ARR). A guide to flood estimation. Institute of Engineers Australia. Vol. 1. I.E. Aust. Canberra. 1987

[9] A. Saleh, A. R. Ghobad and R. Noresin (2011). Evaluation of HEC-HMS methods in surface runoff simulation (case study): Kan watershed, Iran. Advances in Environment Biology, 5(6): 1316-1321, 2011.
[10] Z. Yusop, C.H. Chan and A. Katimon, Runoff characteristics and application of HEC-HMS for modeling stormflow hydrograph in an oil palm catchment. Water Science and Technology Vol 56, No. 8, pp. 41-48, 2007.

[11] DID. (2010), "Hydrological Database, Kuala Lumpur, Drainage and Irrigation Department Malaysia.

[12] Malaysian Meteorological Department (MMD). General Climate of Malaysia. Available: http://www.met.gov.my/index.php [Accessed: February 2010].

[13] J. Suhaila, and A.A. Jemain, Fitting daily rainfall amount in Malaysia using the normal transform distribution, J.Applied. Sci., 7, 1880-1886, 2007.

[14] C. L. Wong, R. Venneker, S. Uhlenbrook, A.B.M. Jamil, Y. Zhou, Variability of rainfall in Peninsular Malaysia, Hydrol. Earth Syst. Sci. Discuss.,6, 5471-5503, 2009.

[15] USACE Hydrologic Modelling System HEC-HMS, "Technical Reference Manual". (2000), www.hec.usace.army.mil/software/ hec-hms. [ Accessed: August 2009 ]

[16] J.E. Nash, and J.V. Sutcliffe, River flow forecasting through conceptual models, part 1: A discussion on principle. J. Hydrol., 10, 282-290, 1970.

[17] M.F. Mahmood, S. Salleh, T.K. Leong, S.K. Teh, “ Hydrological Procedure No. 1: Estimation of the design rainstorm in Peninsular Malaysia (Revised and Updated)" Drainage and Irrigation Department, Malaysia, 1982. 
[18] M. Ilahee, and M.A. Imteaz, Improved Continuing Losses Estimation Using Initial Loss-Continuing Loss Model for Medium Sized Rural Catchments. American Journal of Engineering and Applied Sciences 2(4):796-803, 2009.

[19] D.H. Pilgrim, Some problems in transferring hydrological relation-ships between small and large drainage basins and between regions. Journal of Hydrology, 65, pg 49-72, 1983

[20] D.N. Moriasi, J.G. Arnold, M.W. Van Liew, R.L. Bingner, R.D. Harmel, \& T.L. Veith. Model evaluation guidelines for systematic quantification of accuracy in watershed simulations. Transactions of the ASABE, 50(30, 885-900, 2007.

[21] M.H. Hussein \& A.K. Othman, Soil and water losses in a low intensity rainfall region in Iraq. Hydrological Sciences Journal, $33,3,6 / 1988$
[22] K.M. Loague, K.M. Impact of rainfall and soil hydraulic property information on runoff predictions at the Hillslope scale. Water Resource Research, Vol 24, No. 9, Pg 1501-1510, 1988.

[23] M.A.W. Taylor, and T.Y. Kiat, "Hydrological Procedure No. 11: Design Flood Hydrograph Estimation for Rural Catchments in Peninsular Malaysia”, Drainage and Irrigation Department, Malaysia, 1976.

[24] M.A.W. Taylor, and T.Y. Kiat, "Hydrological Procedure No. 11: Design Flood Hydrograph Estimation for Rural Catchments in Peninsular Malaysia”, Drainage and Irrigation Department, Malaysia, 1976.

\section{PROFILES}

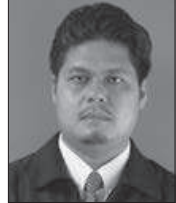

SAZALI OSMAN is a Principal Assistant Director in the River and Coastal Engineering Division, Department of Irrigation and Drainage, Pahang Darul Makmur. He obtained his B.Sc. (Hons) Civil Engineering and Msc. Civil Engineering (Water Resources) from the University Sains Malaysia. His Msc. thesis title is Development of Flood Estimation for Ungauged Catchments using Clark Synthetics Unit Hydrograph Method. He is experienced in hydrological data analysis including flood forecasting model for major rivers throughout Peninsular Malaysia.

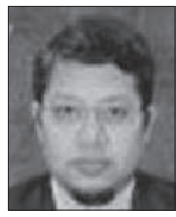

ISMAIL ABUSTAN is a Professor in the School of Civil Engineering, Universiti Sains Malaysia. He obtained his PhD in Civil Engineering (Urban Landuse) from University of New South Wales, Australia in 1997. His main expertise were water quality modelling, hydrology/hydraulic and the water pumping system. He also experienced in various water and environment research project including several collaboration project of government.

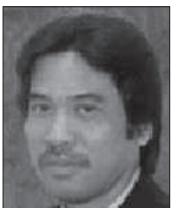

ROZI ABDULLAH is a Associate Professor in the School of Civil Engineering, Universiti Sains Malaysia. He has vast experienced in hydrological data analysis and also data mining using engineering programming software. He is actively doing research project including preparing guidelines and manual for government department. 